\title{
Invasive Plants on Rangelands: A Global Threat
}

\section{By Edward A. Vasquez, Jeremy J. James, Thomas A. Monaco, and D. Chad Cummings}

\section{Introduction to This Special Issue}

he Rangeland Invasive Species Committee is a diverse group who seek to serve the SRM and the public by focusing attention, sharing knowledge, and communicating about rangeland inva-
sive species. As a committee, we envision that the joint meeting of SRM and Weed Science Society of America in 2010 will provide an ideal opportunity to sponsor a special issue of Rangelands to unite many of the key topics regarding invasive rangeland plants and provide a valuable resource to guide rangeland professionals in the future. If looking into the past offers insights into the ecological patterns and processes responsible for the impacts of invasive plants today, an awareness of the current discoveries and conceptual ideas will enrich our understanding of how to proceed in the future and manage rangeland invasive plants.

The series of papers presented here are organized to provoke thought on how rangeland professionals can develop long-term countermeasures for invasive rangeland plants. In its simplest form, the invasion process has four primary stages, including Introduction, Establishment, Spread, and Impact (Fig. 1). ${ }^{1}$ Previous literature suggests that ecological barriers or filters can retard the introduction and expansion of invasive plants. For example, geographical barriers for propagules must be overcome for "Introduction" to occur. Barriers to "Establishment" include biotic and abiotic factors such as species competition and resource availability. Similarly, the "Spread" of invasive plants into new sites requires that individuals survive and produce propagules, which endure in new sites. In the "Impact" stage, invasive plants become dominant and have noticeable effects on ecosystem processes. Furthermore, evolutionary processes (e.g., plastic responses or genetic adaptation to new ecological conditions) may also pose a significant barrier to later stages of invasion across abiotic gradients. ${ }^{2}$ Within this framework it is easy to see that there are many opportunities to affect the invasion process, and we hope this issue helps natural resource professionals identify ways to contribute as well as identify critical needs. To preface this special issue, we briefly highlight a few key factors influencing the expansion of invasive plants on rangelands and the ecological processes that may be involved in driving invasion. In doing so, unifying management strategies can then be designed to target specific ecological processes that influence successional trajectories toward desirable, invasion-resistant plant communities.

\section{Invasive Plants Are Expanding on Rangelands}

Exotic plant species are having impacts on rangelands at an unprecedented rate, ${ }^{3}$ resulting in enormous economic and ecological costs each year. ${ }^{4}$ Human activities and transportation, combined with international trade, allows for rapid movement of people and goods throughout the world. As a consequence, invasive plants have been intentionally and accidentally introduced beyond their native ranges. In addition, because most of the terrestrial land surface has been domesticated by human activities, it is our responsibility toward future generations to develop more effective strategies to prevent introductions and repair ecological processes (e.g., disturbance and resource cycling) that enable invasive plants to establish, spread, and impact rangelands. Unfortunately, in spite of current programs implementing integrated invasive plant management strategies, exotic plant invasion continues globally on rangelands. Clearly, there is a need to aggressively identify and implement measures to prevent further loss to the critical ecosystem services provided by rangelands.

Expansion of invasive plants on rangelands has been attributed to many factors, including traits of the plant and processes within the ecosystem; therefore, forestalling invasion must first identify the underlying causes of invasive plant expansion. Invasive plant traits may include genetic variation and plasticity within a population that enhance performance at the various stages of invasion. Also, high seed production and dispersal ensures propagule pressure to aid in spread, dominance, and ecological impacts of invasive plants. Thus, any physiological and/or morphological traits that allow invasive plants to affect and respond to the immediate environment can increase the rate of spread.

Ecosystem factors such as disturbance, global change, and land fragmentation may also be responsible for invasive 


\section{Exotic seed}
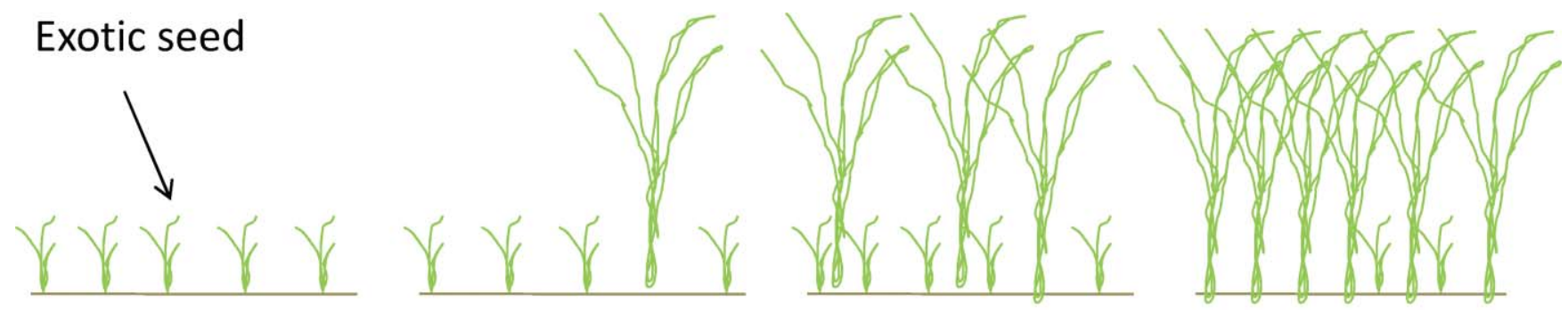

\section{Introduction $\longrightarrow$ Establishment $\longrightarrow$ Spread}

\section{Impact}

Figure 1. Conceptual model of the plant invasion process. Adapted from Levine et al. ${ }^{1}$

plant expansion on rangelands. Many plant species are not limited by dispersal or seed production, but instead by availability of empty or suitable safe sites (niches). Natural and/ or anthropogenic disturbances create safe sites for invasive plants, which is why changes in the severity, frequency, type, and extent of disturbance are commonly implicated in exotic plant invasion. Disturbance functions as a critical ecosystem process that increases site availability and suitability for both native and exotic species, which can initiate, retard, or accelerate plant succession processes. When disturbance becomes more frequent, invasive plant species are often favored because they can more readily preempt soil resources from slower-growing native species. This is especially applicable for invasive annual grasses that respond favorably to the altered disturbance because they 1) complete their life cycle quickly, 2) produce abundant biomass and seed, and 3) perpetuate the fire cycle with seeds that survive the fire. Altered disturbance regimes can also foster invasion by native species as has been the case for western juniper (Juniperus occidentalis var. occidentalis Hook.) in the western United States, which has rapidly expanded its geographic range at unprecedented rates over the last 130 years (postEuropean settlement). The expansion of Western juniper into previous grass- or shrub-dominated rangelands has been attributed to climatic influences, livestock grazing, rising levels of atmospheric $\mathrm{CO}_{2}$, and increased mean annual fire return intervals since the late $1800 \mathrm{~s}^{5}$

Accordingly, global change (e.g., climate, atmospheric $\mathrm{CO}_{2}$, biogeochemical cycling) also appears to be contributing to invasive plant expansion on rangelands. For example, decreased summer precipitation is projected to make portions of the Intermountain West more climatically suitable for invasive annual grasses, while increased precipitation and/or higher winter temperatures may lead to a loss of climatic suitability in other portions. ${ }^{6}$ Similarly, climate change may hinder the spread of European annual grasses in southern Africa, but shift their distribution into pristine areas at higher elevations. ${ }^{7}$ Finally, elevated levels of atmospheric $\mathrm{CO}_{2}$ and atmospheric deposition of nitrogen (dry and wet) have greatly increased in the last 50 years. ${ }^{8}$ Alterations in these important resources for growth and photosynthesis may be favoring the performance of invasive plant species over desired native species.

As urbanization increases, rangelands are becoming increasingly fragmented and surrounded by human development. Rangelands at the wildland-urban interface experience increased levels of erosion or sedimentation through increased water runoff from paved surfaces characteristic of urban areas and are also vulnerable to invasive plants as a result of increased disturbance. In fact, invasive plant establishment and soil nutrient enrichment are two important influences of urban areas at wildland-urban interfaces. ${ }^{9}$ Urban areas also contain many open areas with high levels of disturbance such as roads, which promote establishment of invasive plants through transport via vehicles and animals. Identifying these important vectors should help prevent introduction and spread of invasive plant species and should be an overall primary management goal. Therefore, early detection and containment is critical for preventing the introduction, establishment, and spread into new sites. Once invasive plants become established and spread to new locations, the chance of successfully controlling them is greatly reduced and becomes extremely costly over the long term. Although invasive plants are expanding, many portions of rangelands are not invaded and could benefit by directing energy toward preventing introduction in the first place.

\section{Unifying Management Strategies}

There is little dispute that invasive plants have deleterious economic and ecological impacts on rangelands. These impacts diminish the ability of rangelands to provide goods and ecosystem services (e.g., food, fiber, clean water, wildlife habitat, recreation space). Reducing the impacts of invasive species and repairing rangeland health requires identifying effective unified management strategies that address the underlying ecosystem processes that facilitate the invasion process. Therefore, the SRM Rangeland Invasive Species Committee recognizes that a strong collaborative effort among resource managers and research scientists is needed to deal with this critical issue. The series of articles presented in this special issue of Rangelands is a significant step toward addressing this quandary. Progress in dealing with 
the escalating problems caused by invasive plants on rangelands requires innovative, multidisciplinary collaboration among producers, rangeland management specialists, and ecologists. Comprehensive economic analyses are lacking for most invasive plant species and rangeland restoration practices; furthermore, additional research is needed to quantify ecological effects caused by invasive plants on rangelands. There is a need to identify ecological principles and the conditions in which they hold true that will allow restoration and management efforts to be successful across a range of restoration scenarios. Future research will need to focus on uncertainties, including the effects of multiple simultaneous interactions of stressors (e.g., climate change), long-term atmospheric $\mathrm{CO}_{2}$ enrichment on vegetation, changes in rangeland species composition, extreme climatic events and other disturbances (e.g. fire, drought), and feedback mechanisms that increase or decrease change.

Because invasive plant species usually establish as a result of altered or damaged ecosystem processes, unified invasive plant management strategies should aim to alter ecosystem processes in ways that deter invasive plants and foster the existence of desired rangeland states and resilience. Ecological principles need to be developed and incorporated into a holistic Ecologically Based Invasive Plant Management (EBIPM) framework. ${ }^{10}$ In certain instances we may need to develop novel management strategies to coexist with invasive plants and limit their deleterious impacts on rangelands. A new synergy needs to be implemented with the herbicide industry to develop more specific chemicals for rangeland systems. Recognizing that invasion is not a discrete event, but a continuous process, is fundamentally necessary if individual rangeland professionals are to visualize how to combat this growing threat.

Because of the limited space in Rangelands and the desire to improve the readability of the articles, the number of citations is limited within the text. However, interested readers can have access to the full range of literature that the authors have referenced at www.srmjournals.org. All of the following articles in this special issue were peer-reviewed, and we thank the authors and reviewers for their valued contribution. We sincerely hope this issue provides the rangeland management community with some of the most salient considerations with respect to invasive plants on rangelands.

\section{Acknowledgments}

The SRM Invasive Plants Committee would like to thank the USDA-Agricultural Research Service, the Bureau of
Land Management, and Dow AgroSciences LLC for sponsoring this special issue of Rangelands.

\section{References}

1. Levine, J. M., P. B. Adler, and S. G. Yelenik. 2004. A meta-analysis of biotic resistance to exotic invasions. Ecology Letters 7:975-989.

2. Dietz, H., And P. J. Edwards. 2006. Recognition that causal processes change during plant invasion helps explain conflicts in evidence. Ecology 87:1359-1367.

3. Ваввіт, B. 1998. Statement by Secretary of the Interior on invasive alien species. In: Proceedings, "Science in Wildland Weed Management" Symposium; 8-10 April 1998; Denver, CO, USA. Available at: http://www.nps.gov/plants/alien/pubs/ bbstat.htm. Accessed 5 January 2010.

4. DiTomaso, J. M. 2000. Invasive weeds in rangelands: species impacts, and management. Weed Science 48:255-265.

5. Miller, R. F., J. D. Bates, T. J. Svejcar, F. B. Pierson, and L. E. Eddleman. 2005. Biology, ecology, and management of western juniper. Oregon State University Agricultural Experiment Station, Technical Bulletin 152:10-11.

6. Bradley, B. A. 2008. Regional analysis of the impacts of climate change on cheatgrass invasion shows potential risk and opportunity. Global Change Biology 15:196-208.

7. Parker-Allie, F., C. F. Musil, and W. Thuiller. 2009. Effects of climate warming on the distribution of invasive Eurasian annual grasses: a South African perspective. Climate Change 94:87-103.

8. Knapp, P. A., And P. T. Soule. 1999. Geographical distribution of an 18th century heart rot outbreak in western juniper (Juniperus occidentalis spp. occidentalis Hook). Journal of Arid Environments 41:247-256.

9. Alston, K. P., and D. M. Richardson. 2006. The roles of habitat features, disturbance, and distance from putative source populations in structuring alien plant invasions at the urban/ wildland interface on Cape Penisula, South Africa. Biological Conservation 132:183-198.

10. Sheley, R. L., J. J. James, And E. C. Bard. 2009. Augmentative restoration: repairing damaged ecological processes during restoration of heterogeneous environments. Invasive Plant Science and Management 2:10-21.

Authors are Research Rangeland Management Specialist (Vasquez) and Plant Physiologist (James), USDA-Agricultural Research Service, Eastern Oregon Agriculture Research Center, 67826-A Hwy 205, Burns, OR 97720,USA, ed.vasquez@ oregonstate.edu; Ecologist, USDA-Agricultural Research Service, Forest and Range Research Laboratory, Utah State University, Logan, UT84322, USA (Monaco); and Field Scientist, Oklahoma Region Dow AgroSciences LLC, REPP/IVM and Cereals, 25600 County Rd 110, Perry, OK 73077, USA (Cummings). 